\title{
CONCEPT OF SAGNAC EFFECT APPLICATION IN MEASUREMENT OF ANGULAR ACCELERATION OF PISTON ENGINE CRANKSHAFT
}

\author{
Marek Lutowicz \\ Polish Naval Academy, Mechanical-Electrical Faculty \\ Śmidowicza Street 69, 81-103 Gdynia, Poland \\ tel.: +4858 6262629, fax: +48586262648 \\ e-mail:marek@unitest.pl
}

\begin{abstract}
In the paper results of conducted in Polish Naval Academy researches aiming to diagnostic using of measurement of engine crankshaft unsteady angular speed measurement will be presented. Similar works were many times started in different research centres. Up to now, adequate accuracy of measurement had not been achieved to make proper diagnostic decision. In commercial field, measurement of unsteady rotation speed has been used only in MAPEX-TV system (Torsional Vibration detector) dedicated to SULZER engines, which up to now without any mistakes detected only the one engine cylinder switch out of work. To the advanced diagnostic system, there are a lot off work to do. For several years in navigation, more often are used optic gyroscopes, which work on the base of Sagnac effect, assuring angular speed measurements, with $0.001^{\circ} / \mathrm{h}$ resolution. Such resolution is absolutely higher than needed in piston engines diagnostic, but range of measured rotation speed is much lower than rpm of low speed marine diesel engines. In scope of conducted scientific work, it was decided to build of model of Sagnac interferometer prepared to measure rotational speed in range adequate to medium speed marine diesel engines. At rotational speed, equal $750 \mathrm{rpm} 1 \mathrm{mV}$ change in output voltage had been achieved for the difference of $0.4^{\circ} / \mathrm{sec}$ of rotational speed. Time of measurement is equal the time, which need light to go through distance of $100 \mathrm{~m}$ fibber-optic line. In practice, this method does not introduce any significant phase shifts and does not limit the number of samples per revolution.
\end{abstract}

Keywords: pressure measurement, piston engine, indicating

\section{Introduction}

The Polish Naval Academy in Gdynia has been conducted marine combustion engines indication tests for almost all Polish Navy vessels, main and auxiliary engines on civilian ships and gas engines type GMVH on gas compressor stations since more than 20 years. Up to now as part of the previously conducted in the PNA works, they dealt mainly with processing of indicator diagrams. Due to the high cost and limited durability of the combustion pressure sensors, this method works only in the short-term measurements. [6] In addition to this on board of the Polish Navy ships there are used engines, which are not prepared to the indication tests. Since these engines also should be subject to the diagnostic supervision there is a requirement to develop of alternative diagnostic methods. Several diagnostics methods have been developed based on the measurement of torsional vibration, pulsation pressure in the exhaust duct, envelope accelerations caused by the work of the fuel injectors and intake/exhaust valves.

The operation of piston engine is characterized by torque variation in time. During the work stroke in one cylinder engine gas pressure accelerates the crank system, while during the other strokes the crankshaft angular velocity decreases. To minimize the change in angular velocity multi-cylinder engines are used and they are fitted in relatively heavy flywheels. The measure of inequality of the angular velocity of the engine is angular speed inequality ratio defined as:

$$
\delta=\frac{\omega_{\max }-\omega_{\min }}{\omega_{s r}} .
$$

In typical automotive engines angular speed inequality ratio in the case of correct adjustment reaches values in the range from $1 / 250$ to $1 / 150$. Equally low coefficients of angular speed inequality ratios are reached in auxiliary engines, where the load is balanced and the weight of the 
rotor of the generator also increases the moment of inertia of the flywheel. In the case of marine diesel engines for main propulsion effect of angular speed inequality ratio is the result of interference of engine torque variation of load torque and moment of inertia of the rotating elements of the engine with the propeller shaft, propeller and associated water. Load has changes when the propeller blade passes directly in front of the rudder blade, coming up to the surface of the hull, and in particular as a result of the impact of sea waves.

The instantaneous angular velocity measured with high resolution can be a very useful diagnostic parameter. A dominant influence on the angular acceleration has a total summarized moment of tangential forces, which act on all crankshaft systems, and these in turn depend mainly on the mean indicated pressure of each cylinder.

As part of the research work currently carried out it was decided to separate from the instantaneous velocity course accelerations induced by cyclic engine operation from accelerations caused by uneven load of the engine and the governor operation. The measuring system must provide sufficient resolution without the use of filtering and averaging.

\section{Measurement of angular accelerations}

The most popular is the measurement of the angular instantaneous speed by using optical or inductive sensors with gear/teeth element arranged on the shaft. By calculating the angular speed derivative in time domain it is possible to determine the angular acceleration. Such attempts have been repeatedly made in the past but the results were subject to large errors [1-5].

In the PNA a unique system for measuring of the angular speed, insensitive to inaccuracies in made of the toothed element, has been developed. This error has been eliminated by expanding the measurement system for an additional sensor. Measurement of the time of the marker transition between two sensors spaced apart by an angle slightly less than the angle between the teeth has been done. Both sensors had detected the appearance of the same gaps between marks. Preliminary tests were carried out on the one cylinder engine type KM170 and achieved results were presented at the conference KONES2012 [6]. These results were very encouraging. Clean, undistorted waveforms as shown in Fig. 1 example had been obtained. As expected, the filtering and averaging have been unnecessary.

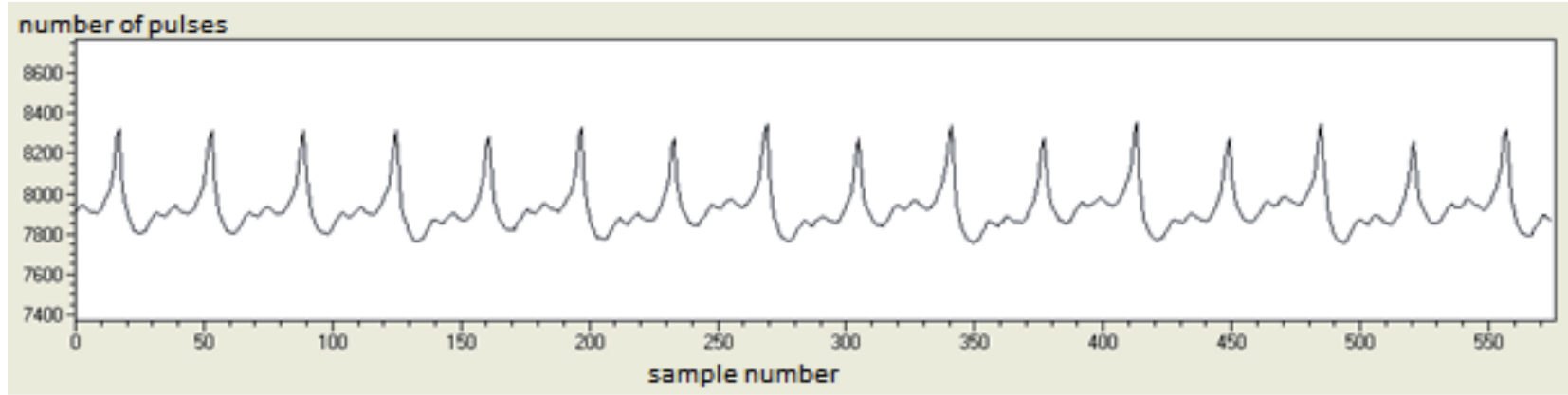

Fig. 1. An example of the measurements results of the time of consecutive markers transition between the sensors on the engine KM170 type at a speed of $2500 \mathrm{r} / \mathrm{min}$ with no load [6]

It was decided to move the measuring system on the 6-cylinder SULZER engine type 6AL20/24. In the case of 6-cylinder engine unsteady of angular speed was significantly smaller and the accuracy of the method has proved to be insufficient. An example of a measurement result of the instantaneous angular speed at this engine is shown in Fig. 2.

There is a presumption that the cause of interference could be vibration of the engine block, which moved to the vibration of optical sensors. It was intended to measure the time of the marker transition between sensors spaced about $25 \mathrm{~mm}$ with resolution above 20000 then the displacement of the sensor for each 2.5 microns was recorded as a change in the time of 2 units. 


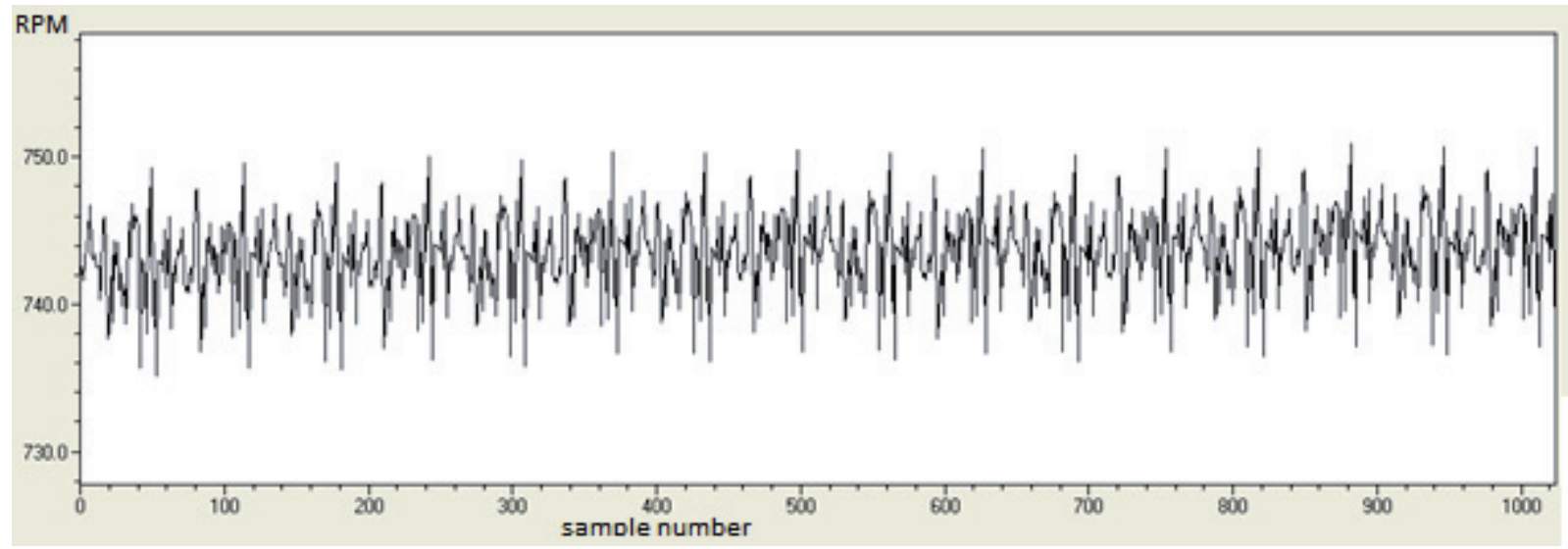

Fig. 2. An example of the measurements result of the SULZER engine 6AL20/24 type shaft angular speed between markers at a speed of $750 \mathrm{rev} / \mathrm{min}$ with no load [6]

The engine block vibrations caused by the cyclic operation of the engine and the surge of the sea can be eliminated by measuring the angular velocity or acceleration with respect to an inertial reference system, which in the simplest case can be freely suspended on the shaft weight.

Angular acceleration by this method can be measured by the special design seismic sensors mounted on the shaft itself. However, the transmitter is simple oscillating system whose frequency response characteristics limits the scope of its applicability, and is the source of the ambiguity of the results of measurement [4].

\section{Methods for measuring the angular velocity using a Sagnac interferometer}

Currently, the most accurate measurements of the distance and the speed are performed by optical methods, which measure interference with resolutions better than the wavelength of light. For example, a Michelson interferometer is so accurate that in 1960-1983 years it served as the definition of the SI meter. To measure of the angular velocity the Sagnac interferometer is used. It is now mainly used in inertial navigation systems in aircrafts, submarines and missiles, among others, in the Norwegian NSM missiles. Devices, using Sagnac interferometer, allows measurement of the angular velocity to a resolution of about 0.0010 / hour and are used as sensors for so-called optical gyroscopes. Due to the simplicity of some versions of these interferometers with slightly worse parameters are so cheap that have been used even in toys.

Historically, the first practical implementation of the Sagnac interferometer is an interferometer RLG (Ring Laser Gyro). It consists of a helium-neon laser chamber, wherein the optical resonator is made of at least three mirrors. One of them is semi-permeable and through this two laser beams go out. After the change of one beam path through the prism so that it is parallel to the second light interference occurs. Bands are formed. In this interferometer Sagnac effect is used, which is characterized in that in the case of rotation of the interferometer about any axis perpendicular to the plane of the triangle formed by the laser beam the different transit times between the mirrors loop are formed resulting in two light beams propagating in opposite directions (clockwise and anticlockwise to loop rotation). So the phase difference $\Delta \Phi$ is formed by turning the interferometer and the apparent speed of beams, as in the Doppler phenomenon are $V+R \omega$ and $V-R \omega$ where: $\omega$ is the speed of rotation around the axis of the interferometer, $V$ is the velocity of light inside the interferometer.

The measurement of the phase difference can be obtained via image analysis of interference of both beams. Rotation on any axis perpendicular to the plane of the triangle formed by the laser beam moves interference bands in proportion to the angular velocity of the interferometer. Scheme of such interferometer with ring resonator and the view of interference bands generated are shown in Fig. 3. 

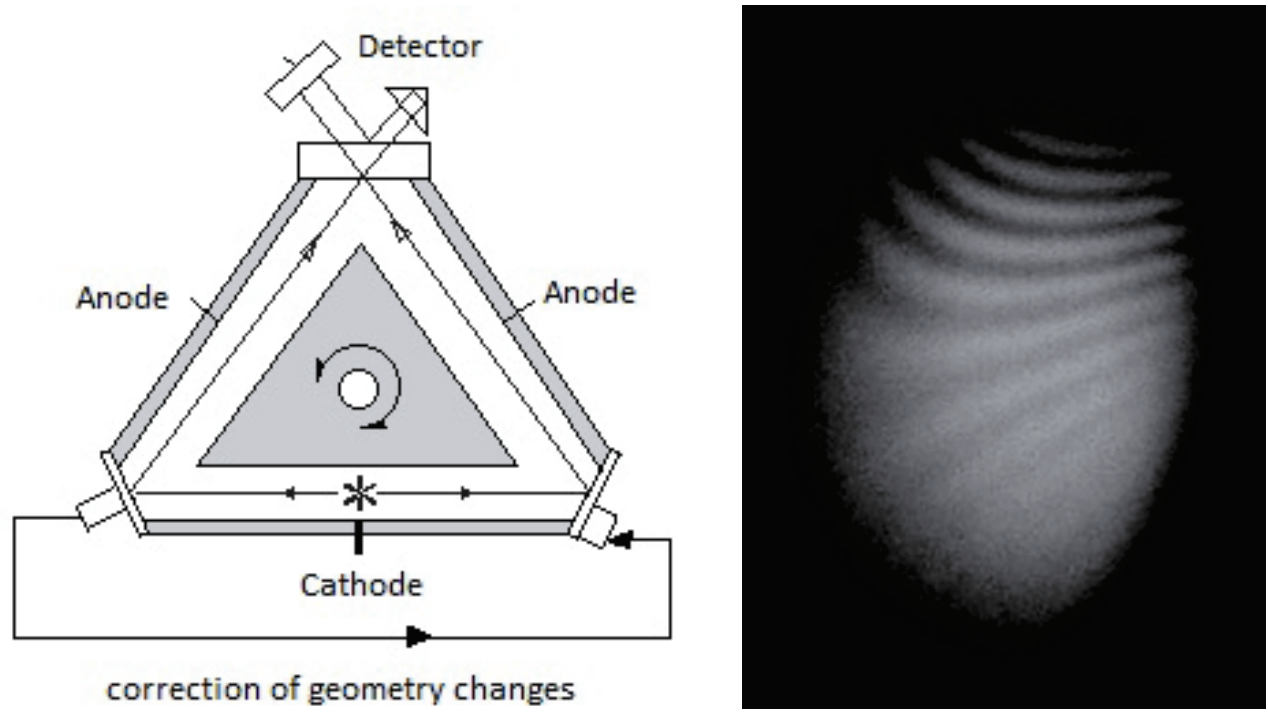

Fig. 3. Schematic view of Sagnac interferometer and interference bands/fringes on the detector [www.ion.org]

This interferometer is insensitive to linear displacement and rotation with respect to any other axis perpendicular to the measurement axis. Although this is a forward-looking technology, due to the severity excludes amateur construction, RLG gyros were excluded from further consideration. It should be noted that it would be ideal sensor, because of the simplicity of calculations and the quality of the measurements.

Sagnac phenomenon is also used in gyroscopes with fiber-optic loop FOG (Fiber Optic Gyro) as shown schematically in Fig. 4.

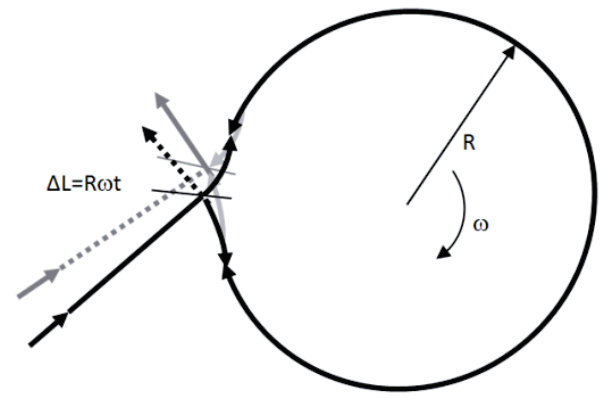

Fig. 4. Schematic of the Sagnac interferometer with fiber-optic loop

Light from a laser source before entering the fiber is separated in to two bundles, one of which runs in accordance with the movement of the rotating angular speed $\omega$, and the other counter clockwise. During the course the beams interfere with each other. The rotational speed of the loop, similar as in RLG (Ring Laser Gyro) interferometer, has an impact on the phase shift between the beams propagating in opposite directions. Since both the beam comes from a single point does not arise interference fringes. Here the modulation subject is only brightness of light, and the difference in distance, which results from the rotation speed, determines the nature of the interference. The intensity of the output light is measured with the photodiode. The dependence of the amplitude of the voltage across the photodiode as a function of the phase shift between the light beams was calculated with formula 1.

$$
I=I_{0} \frac{(1+\cos (\Delta \phi))}{2}
$$

where:

I - light wave intensity (voltage on the photodiode),

$\Delta \phi-$ phase shift. 
In order to increase the measurement efficiency numbers of windings of the fiber are increased. Then the phase shift between the beams describes the formula 2 .

$$
\Delta \phi=\frac{2 \pi L D \omega}{\lambda c}
$$

where:

$\mathrm{L}$ - length of the fiber[m],

- diameter of the coils[m],

$\lambda$ - light wavelength[m],

c - velocity of light $300 \cdot 10^{6}[\mathrm{~m} / \mathrm{s}]$,

$\omega$ - angular velocity $[\mathrm{rad} / \mathrm{s}]$.

After converting the formula, angular velocity $\Omega \pi$ has been determined for which $\Delta \phi=\pi$. Turnover at this speed turns off the light at the output:

$$
\Omega_{\pi}=\frac{\lambda c}{2 L D} .
$$

This speed rate determines the measurement range of the interferometer. Practically you can get any finite value of the $\Omega \pi$ choosing: a light source of a specific length, fiber length and diameter of the fiber loop.

Calculated intensity of the light wave as a function of the angular velocity is shown in Fig. 5.

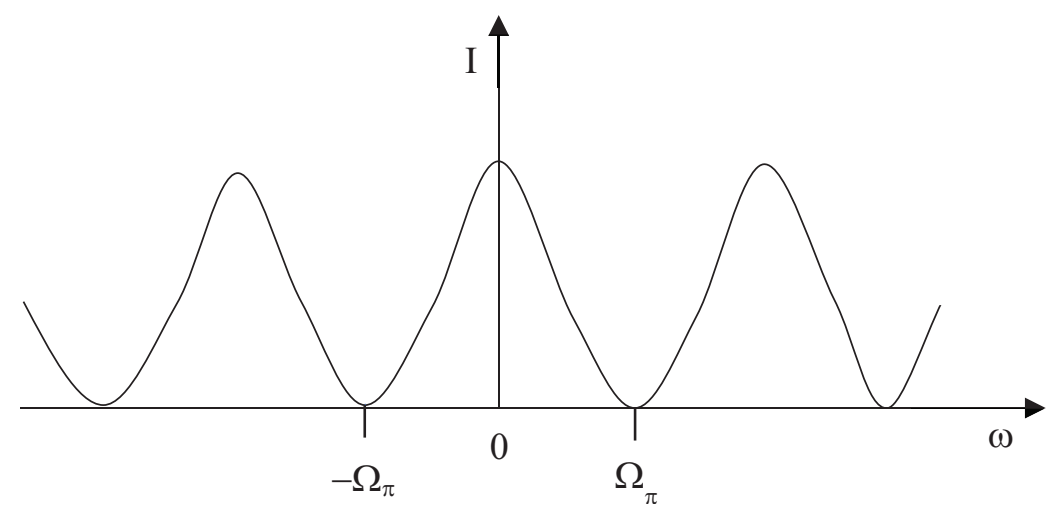

Fig. 5. Brightness of the light being interference effect as a function of the angular velocity [7]

In the commercially, available optical gyroscopes, fibres of lengths of more than $2 \mathrm{~km}$ are used and optimize them into account to improve the accuracy particularly at extremely low speeds. Sample specifications of professional FOG type gyroscopes are presented in Tab. 1.

Tab. 1. Specifications of professional FOG type gyroscopes specified by the manufacturers [www.acielo.com, www.fizopika.ru]

\begin{tabular}{|l|c|c|c|c|c|}
\hline \multirow{2}{*}{ Type of gyroscope } & \multicolumn{3}{|c|}{$\omega_{\max }$} & \multicolumn{2}{c|}{ Random error } \\
\cline { 2 - 6 } & $\circ / \mathrm{h}$ & $\mathrm{rad} / \mathrm{s}$ & $\mathrm{rev} / \mathrm{min}$ & $\% / \mathrm{h}$ & $\%$ \\
\hline Acielo FOG 24 & 100 & 0.00048 & 0.0046 & 0.002 & 0.00002 \\
\hline Acielo FOG 52 & 1200 & 0.0058 & 0.0556 & 0.05 & 0.000042 \\
\hline Fizoptika VG091A & 1080000 & 5.24 & 50 & 10 & 0.00093 \\
\hline
\end{tabular}

As it is clear from the statement offered with FOG type gyroscopes for the intended use in navigation they are optimized to obtain resolution of less than $1^{\circ} /$ hour. This optimization is done at the expense of the measuring range, which does not exceed $0.05 \mathrm{rev} / \mathrm{min}$ for high-performance gyroscopes Acielo type. Only the cheapest on the market and also the worst in terms of navigation gyroscope VG091A type has a measuring range of $50 \mathrm{rev} / \mathrm{min}$, which is close to the range 
required for the measurement of slow-speed marine diesel engines. In the case of medium speed marine diesel engines range as the gyroscope has is too small. It is possible to build a FOG type interferometer using typical elements of fiber optics used in telecommunications, connected according to the diagram shown in Fig. 6.

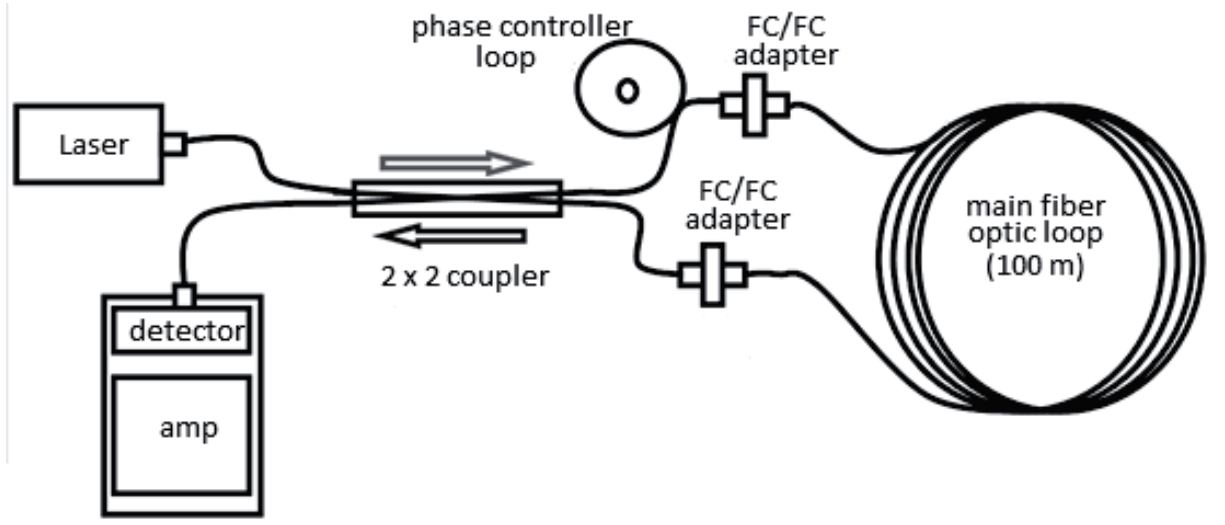

Fig. 6. Schematic of FOG type gyroscope based on typical elements of telecommunications fiber optics [8]

For the planned test bench it was assumed that the fiber could be wound on the existing shaft connecting the engine with brake with a diameter of $0.11 \mathrm{~m}$. The light source is a laser diode with a light wavelength of $1300 \mathrm{~nm}$, and the maximum angular velocity of the engine for which it is possible to explicitly transform the intensity of the light wave at the speed $\Omega \pi=1000 \mathrm{rev} / \mathrm{min}$, i.e. $104.7 \mathrm{rad} / \mathrm{s}$ Transforming the formula 3 into a 4 it can be obtained correlation, which sets the required length of the fiber.

$$
\begin{gathered}
L=\frac{\lambda c}{2 D \Omega \pi}, \\
L=\frac{1300 \cdot 10^{-9} \cdot 300 \cdot 10^{6}}{2 \cdot 0.11 \cdot 104,7}=17[\mathrm{~m}] .
\end{gathered}
$$

Then the detector voltage varies as shown in Fig. 7. It contains a constant component caused mainly by the unequal distribution of the light beam through the coupler and reflections from the points of discontinuity of the fiber.

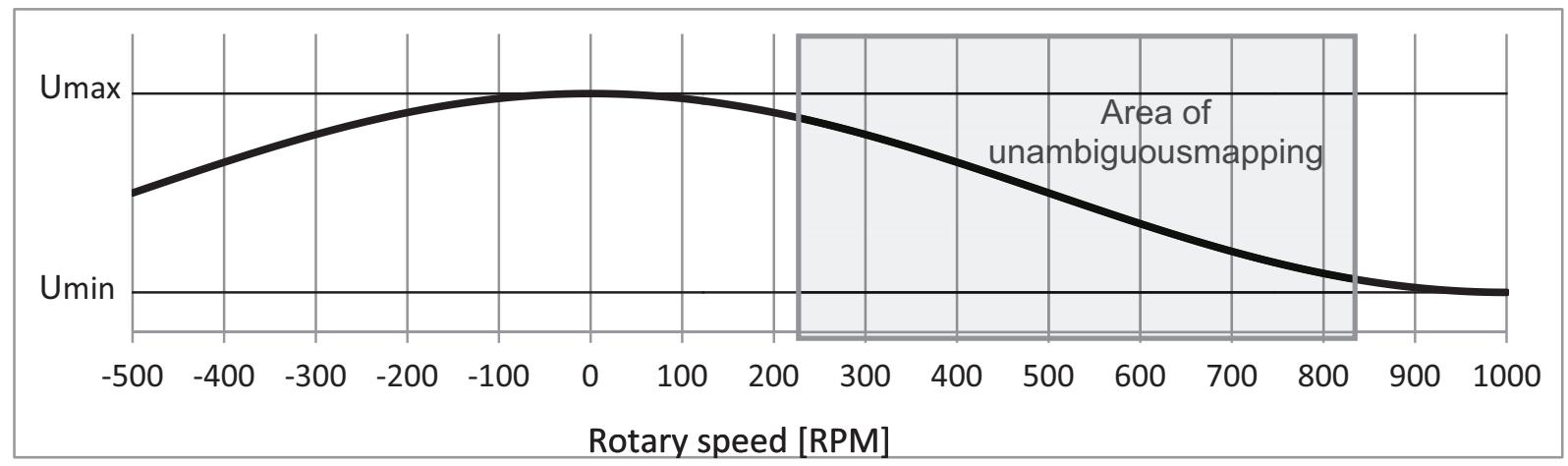

Fig. 7. Light intensity as a function of the rotary speed for the loop length of $17 \mathrm{~m}$

This voltage can be explicitly converted to a rotational speed according to the formula:

$$
n=\cos ^{-1}\left(2 \frac{U-U_{\min }}{U_{\max }-U_{\min }}-1\right) \frac{\omega_{\pi}}{\pi}
$$

where $\Omega \pi$ is expressed in rev / $\min$.

Assuming that the measured speed rate falls within the range of 500 to $1000 \mathrm{rev} / \mathrm{min}$ it may be adopted $\Omega \pi=500 \mathrm{rev} / \mathrm{min}$. Then the phase shift for the speed of $1000 \mathrm{rpm}$ is equal of $2 \pi$. Such 
a change can be achieved by extending of the fiber to $33.9 \mathrm{~m}$ Then for speeds in the range of about 100 to $400 \mathrm{rpm}$ formula of voltage dependence is described by equation 5, while in the range 600 to 900 on the photodiode voltage conversion speed is clearly described with the formula 6 .

$$
n=2 \Omega_{\pi}-\cos ^{-1}\left(2 \frac{U-U_{\min }}{U_{\max }-U_{\min }}-1\right) \frac{\omega_{\pi}}{\pi} .
$$

This will provide a dabble increase in resolution. However, for accurately calculating the speed you need other methods to determine its approximate value to determine which formula should be used. In the area of about 400 to $600 \mathrm{rpm}$ due to the slight inclination and slope course the calculation of the clear value of speed is virtually impossible.

By extending the fiber to $170 \mathrm{~m}$ it can be obtained light intensity dependence which reaching the detector as shown in Fig. 8.

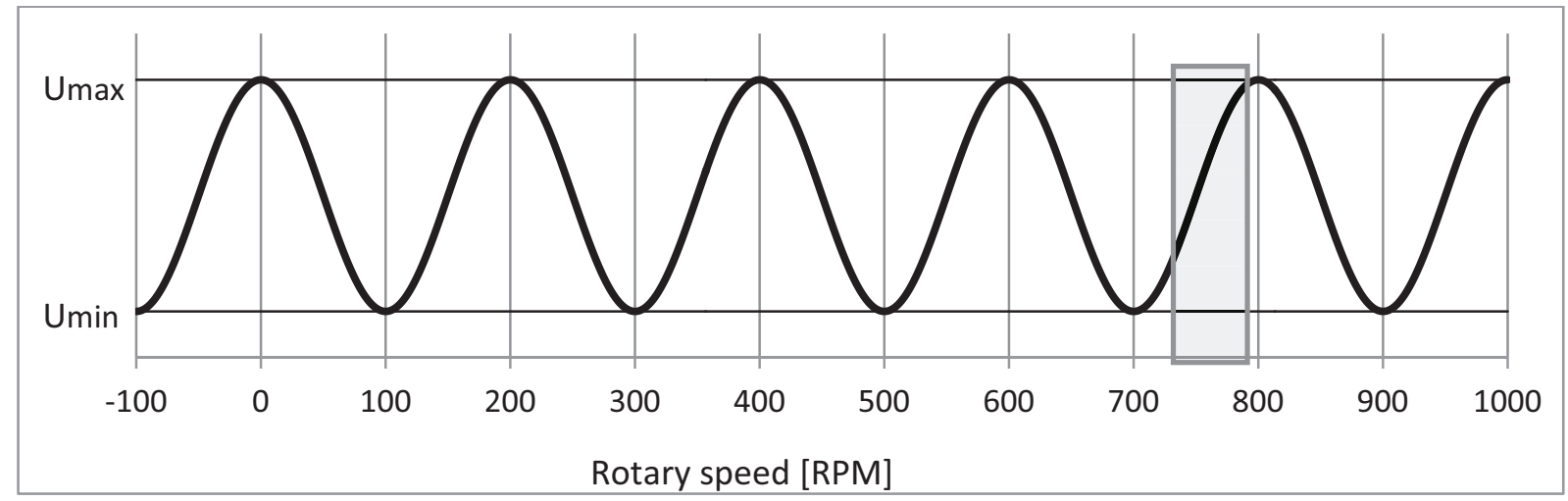

Fig. 8. Light intensity as a function of the rotary speed for the loop length of $170 \mathrm{~m}$

This time that will ensure 10 -fold increase in resolution, but unequivocal mapping of the photodiode voltage in the rotation speed is only possible in a range of about $\pm 30 \mathrm{rev} / \mathrm{min}$ according to expected speed such as $750 \mathrm{rev} / \mathrm{min}$.

\section{Conclusions}

1. Among the analysed methods of measuring, the most promising seem to be FOG gyroscope to measure velocity relative to an inertial reference system, which should ensure uninterrupted measurement of vibrations caused by the engine block work and the surge of the sea.

2. The most prospective in application to measure the rotational speed of the crankshaft were to Professional FOG gyroscopes, if they had the appropriate range of the measured velocity, however, despite the potential technical capabilities widely available optical gyroscopes are not working at the required speed range.

3. You can build FOG gyroscope based on typical telecommunications elements of fiber optic. Limited to measurements in specific ranges of speeds can greatly simplify the design of the gyroscope and increase its resolution.

\section{References}

[1] Wajand, J., Pomiary szybkozmiennych ciśnień w maszynach tłokowych, Wydawnictwa Naukowo-Techniczne, Warszawa 1974.

[2] Dereszewski, M., Analiza prędkości katowej wału korbowego jako metoda dtugoterminowego monitoringu jakości pracy silnika, Zeszyty Naukowe Akademii Morskiej w Szczecinie, Nr 28(100), Szczecin 2011.

[3] Dereszewski, M., Badania możliwości pozyskiwania informacji diagnostycznej o pracy silników okrętowych I układów napędowych na podstawie dyskretnie mierzonej prędkości 
katowej, Zeszyty Naukowe Akademii Morskiej w Gdyni, Nr 78, Gdynia 2012.

[4] Praca Zbiorowa, Indykowanie silników, AVL, 2004.

[5] Piętak, A., Borkowski, W., Analiza pomiarów prędkości obrotowej i obliczeń przyspieszeń kątowych wału korbowego do celów diagnostycznych, SILWOJ'99, Jurata 1999.

[6] Łutowicz, M., Unsteady angular speed of diesel engine crankshaft preliminary examination, Journal of KONES, Vol. 19, No. 4, pp. 393-399, Warsaw 2012.

[7] Gucma, M., Podstawy morskiej nawigacji inercyjnej, Akademia Morska w Szczecinie, Szczecin 2006.

[8] Skyhunt, SKY-SAGNAC manual Rev.A, 05/2013. 